\title{
THE EFFECT OF CRISES ON FIRM EXIT AND THE MODERATING EFFECT OF FIRM SIZE
}

\author{
Celeste AMORIM VARUM ${ }^{1}{ }^{+}$(camorim@ua.pt) \\ Department of Economics, Management and Industrial Engineering, GOVCOPP, University of Aveiro \\ 3810-193 Aveiro \\ Portugal \\ Telephone: 00351234370200 (ext. 23633) \\ Fax: 00351234370215 \\ Vera Catarina ROCHA (verarocha@ua.pt) \\ Department of Economics, Management and Industrial Engineering, University of Aveiro \\ 3810-193 Aveiro \\ Portugal \\ Telephone: 00351234370200 \\ Fax: 00351234370215
}

\begin{abstract}
The liability of smallness assumption suggests that smaller firms face higher exit risks. However, does it apply during crises? We show that during downturns size reduces firms' exit risk by less; the hazard rate increases more rapidly in size.
\end{abstract}

Keywords: survival; hazard; firm size; crisis; manufacturing; Portugal

JEL Codes: D21, E32, L25, L60

\footnotetext{
1 Corresponding author:

Celeste Amorim Varum (camorim@ua.pt)

University of Aveiro

Department of Economics, Management and Industrial Engineering

3810-193 Aveiro

Portugal

Telephone: 00351234370361 (ext. 23633)

Fax: 00351234370215

+ Visiting researcher at Politecnico di Milano, Italy
} 


\section{INTRODUCTION}

Several influential surveys claim the emergence of a stylized fact showing that firm size is correlated with firm survival and exit (e.g., Geroski, 1995; Manjón-Antolín and Arauzo-Carod, 2008). Smallness tends to increase firm exits (Grilli et al., 2010; Pérez et al., 2004), since firms entering the market on a relatively small scale may face cost disadvantages and greater difficulties in accessing capital and labor markets compared with wellestablished firms. However, we still know little about the survival patterns of firms during a crisis period.

Several reasons explain why smaller firms may also show higher exit rates during crises. Smaller firms may be more severely affected by crises due to limited financial, technological and human resources and greater dependence on (fewer) customers, suppliers and markets (Beck et al., 2005; Butler and Sullivan, 2005; Gertler and Gilchrist, 1994). Conversely, smaller enterprises may be more flexible in adjusting to downturns, being more able to exploit market niches and activities characterized by agglomeration economies, rather than scale economies, and being less reliant on formal credits compared with larger firms and thus less inert and less subjected to sunk costs (Liu et al., 1999; Tan and See, 2004).

In this paper we assess whether firm size contributes to differentiating firm exits during crises, also controlling for other determinants that may affect firm exits. Indeed, other firm characteristics, among which are age, human capital, performance, ownership and location, as well as industry specificities, may affect firm survival (e.g., Agarwal, 1996; Audretsch, 1995; Boeri and Bellman, 1995; Ericson and Pakes, 1995; Littunen, 2000). The use of a unique data set helps us to overcome a gap in the literature regarding the importance of size to firm survival during economic downturns.

\section{DATA AND METHODOLOGY}

We use data from a longitudinal database, 'Quadros de Pessoal', from GEP of the Portuguese Ministry of Labor and Social Solidarity. The database collects data from a compulsory questionnaire sent to all firms with wage earners in Portugal since 1982. We follow Mata and Portugal's (2002) procedures to identify entries and exits. We focus on the 1988 cohort and manufacturing firms born thereafter, relying on discrete duration models (Singer and Willett, 1993), since conventional approaches such as linear regression or binary choice models are ill-suited to conducting survival analyses properly. We estimate a piecewise constant hazard model, in which the exit rates are assumed to be constant within each interval (year), but different between intervals. The hazard function in interval $t$, accounting for the effects of covariates, is defined as:

$$
\mathrm{h}\left(\mathrm{t} \mid \mathbf{X}_{\mathrm{t}-1}\right)=\exp \left(\lambda_{\mathrm{t}}\right) * \exp \left(\beta \mathbf{X}_{\mathrm{t}-1}\right), \quad \mathrm{t}=1, \ldots, \mathrm{T}
$$

where the sequence of $\exp \left(\lambda_{t}\right)$ gives the evolution of the exit rates and $\beta$ denotes the vector of coefficients associated with a set of explanatory variables (namely, firm and industry characteristics and macroeconomic control (Table 1)). The effect of covariates upon hazard rates is assumed to be proportional (Cox, 1972), as the following reparameterization, estimated by maximum likelihood methods, shows: 
$\log \mathrm{h}\left(\mathrm{t} \mid \mathbf{X}_{\mathrm{t}-1}\right)=\lambda_{\mathrm{t}}+\beta \mathbf{X}_{\mathrm{t}-1}, \mathrm{t}=1, \ldots, \mathrm{T}$

\section{Table 1 here}

\section{EMPIRICAL RESULTS}

We identified two downturn periods in the Portuguese economy - 1991-93 and 2001-03 - characterized by declines in GDP, consumption and investment and increases in unemployment. Our final data set comprises 87,027 firms at risk of exiting, belonging to 18 cohorts (1988-2005), from which 55,622 exits were identified (551 exits among large enterprises (LEs)). Using the European definition of SMEs, according to which a firm is considered an SME if it employs fewer than 250 persons and if its annual turnover does not exceed 50 million euro or its balance sheet does not exceed 43 million euro (EC, 2005), SMEs represented $98 \%$ of the total number of manufacturing firms in 1988, accounting for $64 \%$ of employment and $42 \%$ of total sales. Two decades later, the shares for SMEs were respectively $99 \%, 79 \%$ and 49\%, which justifies the concern of the government regarding the SME sector. Figure 1 depicts Kaplan-Meier estimates (Kalbfleish and Prentice, 1980) comparing SMEs and LEs. Table 2 presents the average values for the main variables, for all firms and for the separate groups of SMEs and LEs.

\section{Figure 1 and Table 2 here}

The median survival time is 5 years for SMEs and 10 years for LEs. The differences are statistically significant at the $1 \%$ level. We then carried out a multivariate analysis, estimating a discrete time hazard model controlling for firm and industry specificities, searching for a potential different behavior between SMEs and LEs during economic slowdowns (Table 3).

\section{Table 3 here}

We find a negative but non-linear U-shaped relationship between firm size and exit, as Figure 2 depicts. However, during downturns, the marginal negative impact of the size on the hazard rate seems to decrease (the interaction term Size*Downturn, which assesses whether and in which direction firm size moderates the impact of economic slowdowns, is positive and significant at the $1 \%$ level), so an increase in size reduces the hazard rate by less during downturns than it does during non-downturn periods.

Moreover, the results show that the "minimum hazard size" is smaller during downturns (about 225 versus 335 employees) and that with larger sizes, the hazard risks increase more rapidly in size than in non-downturn years. The results thus suggest that recessions increase the likelihood of exiting for both smaller and larger firms. However, during crises, despite large firms still being less likely to exit than their smaller counterparts, their likelihood of exiting increases more than that of SMEs relative to their respective exit probabilities in non-crisis periods. Additionally, the maximum size for an SME lies in the range of hazard minimum sizes [225, 335], potentially suggesting that in prosperous years "big" SMEs may have survival advantages over LEs. This hypothesis necessitates future and deeper research on this moderating effect arising from firm size on the business cycle, as an "optimal size range" might exit in order for firms to thrive during a crisis. 


\section{Figure 2 here}

\section{CONCLUSION}

Despite the wide literature on the firm size-survival nexus, we still know little about this relationship during crises. We analyzed the moderating effect of firm size on firm exit during recessions for Portugal, where SMEs account for a very significant share of the number of firms, employment and turnover. The results show that exits are countercyclical and recessions act as a catalyst for firm exits. Moreover, there is a moderating effect played by firm size. In fact, during downturns, the firm size reduces the exit risk by less than during nondownturn periods and the hazards seem to increase more rapidly in size during recessions than during nonrecession years. The study thus suggests that large firms suffer a greater increase in exit hazard during downturns than smaller firms do, although small firms remain generally more likely to exit. Accordingly, largeness is less helpful in avoiding exits in a crisis context, as a large size may be responsible for firm inertia and an inability to adapt optimally to an adverse environment.

\section{Acknowledgements}

*We acknowledge GEP (Gabinete de Estratégia e Planeamento) from the Ministry of Labor and Social Solidarity for allowing the access to the original data. The data analysis, results and conclusions are of the authors' own responsibility. The first author acknowledges the Sabbatical Grant from the Portuguese Fundação para a Ciência e Tecnologia (FCT) [SFRH/S=BSAB/ 920/2009].

\section{References}

Agarwal, R., 1996. Technological activity and survival of firms. Econs. Lett. 52, 101-108.

Audretsch, D., 1995. Innovation, growth and survival. Int. J. Ind. Organ. 13, 441-457.

Beck, T., Demirgüç-Kunt, A., Maksimovic, V., 2005. Financial and legal constraints to growth: does firm size matter?. J. Financ. 60, 1, 137-177.

Boeri, T., Bellman, L., 1995. Post-entry behaviour and the cycle: evidence from Germany. Int. J. Ind. Organ. 13, 483-500.

Butler, J., Sullivan, J., 2005. Crisis response tactics: U.S. SMEs' responses to the Asian financial crisis. J. Bus. Entrep. 17, 2.

Cox, D., 1972. Regression models and life tables. J. R. Stat. Soc. B 34, 187-220.

Ericson, R., Pakes, A., 1995. Markov-perfect industry dynamics: a framework for empirical work. Rev. Econ. Stud. 62, 53-82. 
European Commission, 2005. The New SME Definition. User guide and model declaration. European Commission Publications, Enterprise and Industry.

Geroski, P., 1995. What do we know about entry?. Int. J. Ind. Organ. 13, 421-440.

Gertler, M., Gilchrist, S., 1994. Monetary policy, business cycles, and the behavior of small manufacturing firms. Q. J. Econ. 109, 2, 309-340.

Grilli, L., Piva, E., Lamastra, C., 2010. Firm dissolution in high-tech sectors: an analysis of closure and M\&A. Econs. Lett., doi: 10.1016/j.econlet.2010.07.006.

Kalbfleisch, J., Prentice, R., 1980. The Statistical Analysis of Failure Data. Wiley, New York.

Littunen, H., 2000. Networks and local environmental characteristics in the survival of new firms. Small Bus. Econ. 15, 59-71.

Liu, J., Tsou, M., Hammitt, J., 1999. Do small plants grow faster? Evidence from the Taiwan electronics industry. Econs. Lett. 65, 121-129.

Manjón-Antolín, M., Arauzo-Carod, J. 2008. Firm survival: methods and evidence. Empirica 35, 1-24.

Mata, J., Portugal, P., 2002. The survival of new domestic and foreign-owned firms. Strateg. Manag. J. 23, 323562.

Pérez, S. E., Llopis, A. S., Llopis, J. A. S. (2004). The determinants of survival of Spanish manufacturing firms. Rev. Ind. Organ. 25, 251-273.

Singer, J., Willett, J., 1993. It's about time: using discrete-time survival analysis to study duration and the timing of events. J. Educ. Stat. 18, 2, 155-195.

Tan, H., See, H., 2004. Strategic reorientation and responses to the Asian financial crisis: the case of the manufacturing industry in Singapore. Asia Pac. J. Manag. 21, 189-211. 


\section{Tables}

Table 1. Variables

\begin{tabular}{|c|c|c|}
\hline Core variable & Size*Downturn & Interaction between firm size and downturn periods \\
\hline \multirow{8}{*}{ Firm-Level } & Size & Ln (no. employees) \\
\hline & $\operatorname{Size}^{2}$ & Squared value of Ln (no. employees) \\
\hline & $\mathrm{Age}^{\mathrm{a}}$ & No. years since the firm entry \\
\hline & $\mathrm{Age}^{2}$ & Squared no. years since the firm entry \\
\hline & Ownership & Dummy $=1$ if, at least, $50 \%$ of the capital is held by foreign investors, 0 otherwise \\
\hline & Firm Performance & Ln (Firm Turnover / Firm Employment) \\
\hline & Human Capital & No. workers with a college degree / Total no. workers \\
\hline & Urban & Dummy $=1$ if the firm operates in the districts of Porto or Lisbon, 0 otherwise \\
\hline \multirow{8}{*}{ Industry-Level } & MES & Median of 2-digit industry's employment (Minimum Efficient Scale) \\
\hline & HH Index & Sum of the squared share of FF in total 2-digit industry's employment \\
\hline & Industry Agglomeration & Share of 2-digit industry's employment in total Manufacturing employment \\
\hline & Foreign Share & Share of FF's employment in total 2-digit industry's employment \\
\hline & Export Intensity ${ }^{\mathrm{b}}$ & 2-digit industry Exports / 2-digit industry GVA \\
\hline & Industry Growth & Ln (2-digit industry Employment $\left.t_{t}\right)$ - Ln (2-digit industry Employment $\left.t_{t-1}\right)$ \\
\hline & Entry Rate & Entrants' employment in year $\mathrm{t}$ / 2-digit industry total employment in year $\mathrm{t}$ \\
\hline & Industry Dummies & Dummy $=1$ for each 2-digit industry where the firm operates, 0 otherwise \\
\hline Macro-Level & Downturn & Dummy = 1 for $1991,1992,1993,2001,2002,2003,0$ otherwise \\
\hline
\end{tabular}

a When data for the foundation year was not available, we considered the year of admission of the first worker entering the firm.

${ }^{\mathrm{b}}$ Data on Exports and Gross Value Added is from National Institute of Statistics and Bank of Portugal, respectively.

Table 2.Descriptive Statistics

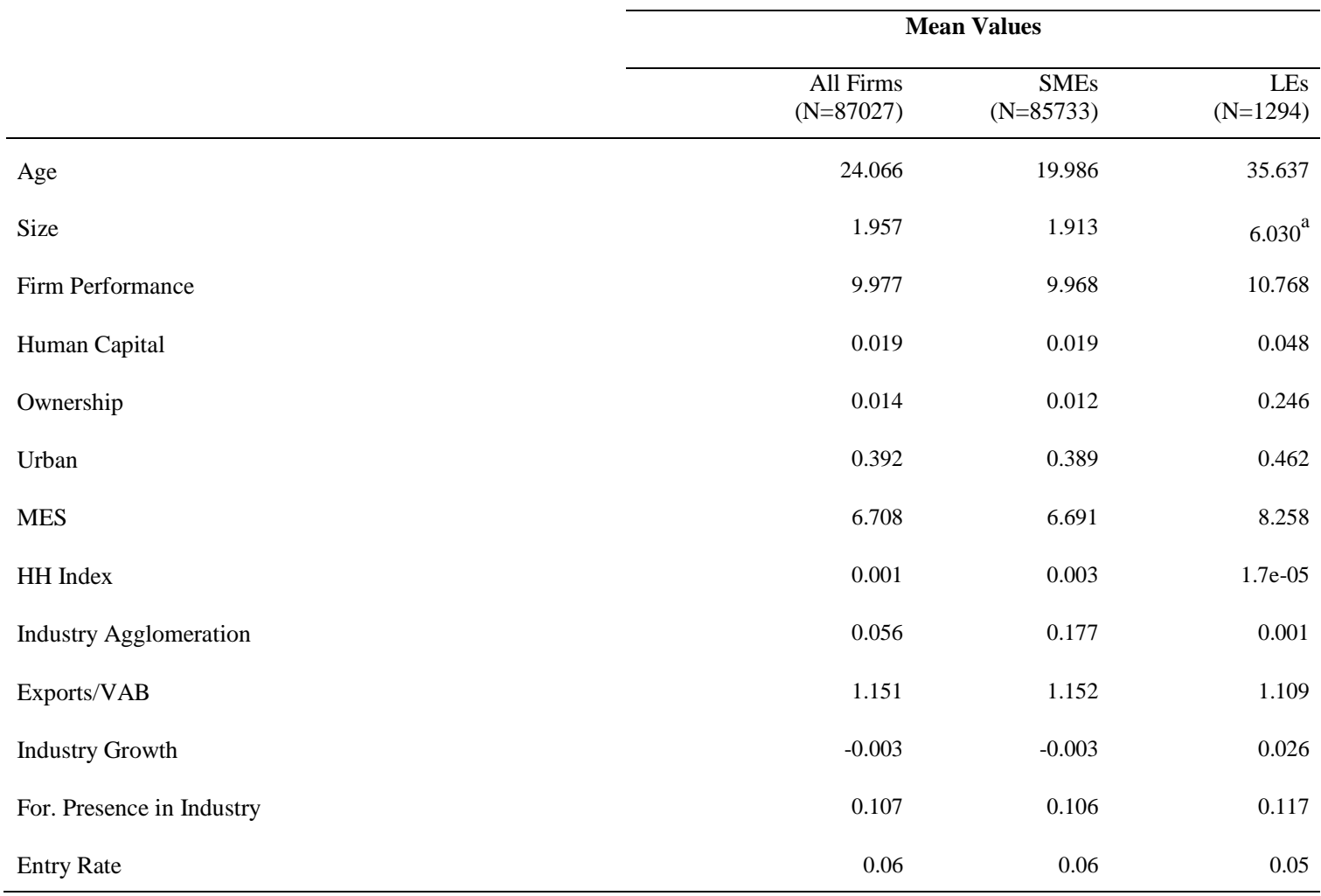

${ }^{a}$ The maximum size attained by LEs in the sample was around 9, that is, above 8100 employees. 
Table 3. Estimation Results ${ }^{\text {a }}$

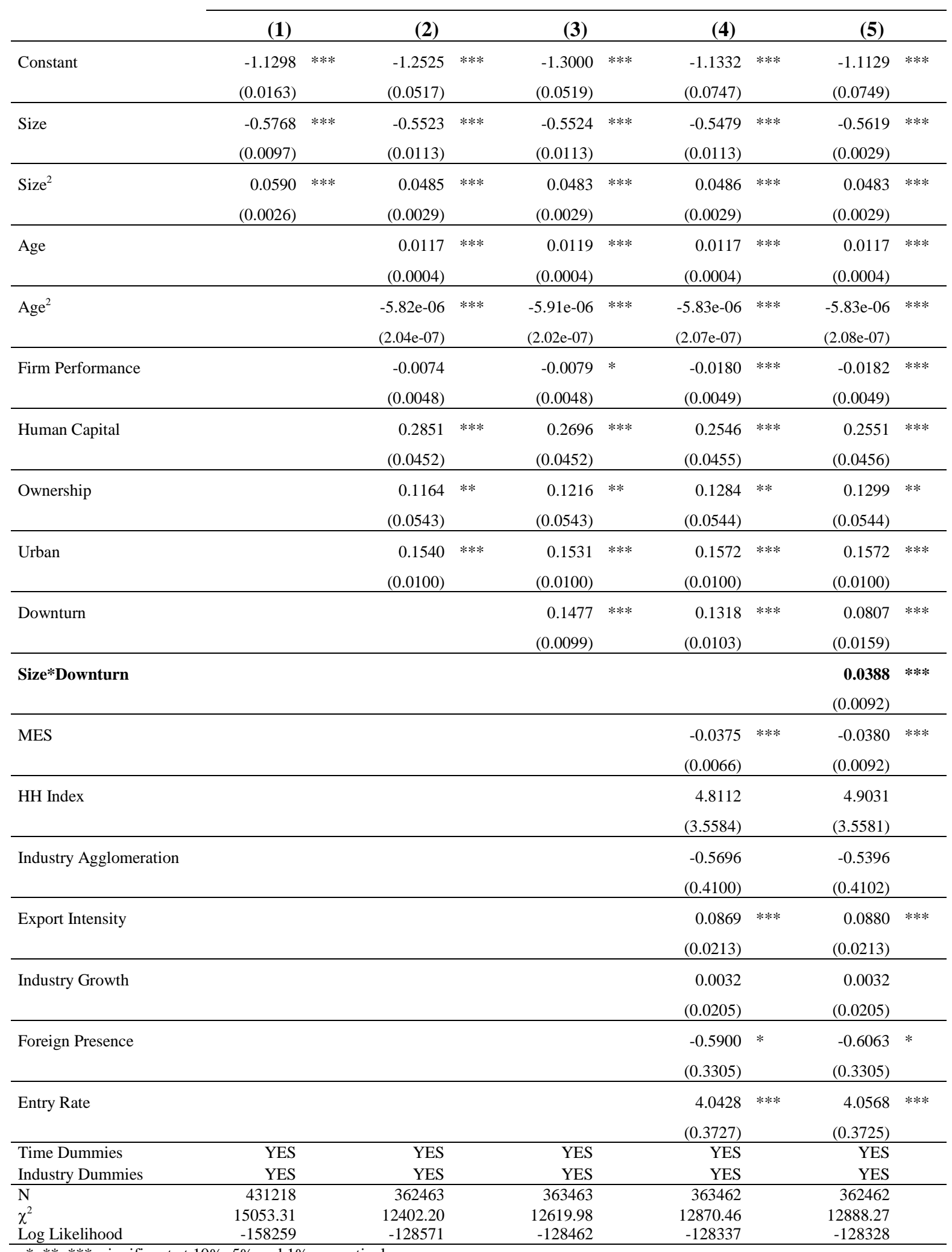

$*, * *, * * *$ : significant at $10 \%, 5 \%$ and $1 \%$ respectively.
${ }^{\text {a }}$ Additionally, we also tested non-linear effects of firm size during crises, but no significant differences were found.

Results are available upon request. Unobserved heterogeneity potential problems were also tested using the program pgmhaz 8 in Stata11®, created by Stephen Jenkins (Jenkins, 2004: Survival Analysis, lecture notes (draft book). Essex university summer school course of survival analysis.). No significant problems of unobserved heterogeneity were found. To interpret the results in terms of odds ratios, we must simply 
analyze the exponentiated coefficients $-\exp (\beta)$. For instance, for the downturn dummy variable, $\exp (0.0807)=1.084$ means that the conditional probability of exit is $8.4 \%$ higher during downturns than during non-downturn periods. Odds ratios above one are thus associated with variables that increa 